\section{Effect of salt tolerant Bacillus sp. and Pseudomonas sp. on wheat (Triticum aestivum L.) growth under soil salinity: A comparative study}

\author{
Shobhit Raj Vimal, Jaya Gupta, \\ Jay Shankar Singh \\ Department of Environmental \\ Microbiology, Babasaheb Bhimrao \\ Ambedkar University, Lucknow, Uttar \\ Pradesh, India
}

\begin{abstract}
This study was conducted to examine the comparative effect on wheat plant health inoculated with the two different rhizobacterial strains Bacillus sp. (JG3) and Pseudomonas sp. (JG7) under soil salinity. Total seven potential salt tolerant strains were isolated from the saline soils of BBAU-Lucknow. The bacterial strains have been investigated for nitrogen fixation, phosphate solubilization, ammonia, indole acetic acid and hydrogen cyanide production activities. Based on morphological and biochemical activities the strains JG3 was designated as Bacillus sp. and the strain JG7 was designated as Pseudomonas sp. Both the strains witness positive for the different plant growth promoting traits. In comparison of strain JG7, strain JG3 inoculated wheat seeds enhance plant height by $32.32 \%$, root length by $37.84 \%$, fresh weight by $28.2 \%$ and dry weight by $15.51 \%$ in FYM amended soils. We observe in this study that seeds treated with Bacillus sp. found significantly effective in plant growth promotion compared to Pseudomonas sp. in saline soil. Based on the comparative experimental study reported herein, it is pointedly observed that the use of salt tolerant PGPRs are effective for facilitating plant health in salt stress environments.
\end{abstract}

\section{Introduction}

Salinity is one of the most common environmental stress factors that adversely affect plant growth and crop production in cultivated areas worldwide. ${ }^{1,2}$ Primary saline conditions appear naturally in environment yet anthropogenic activities are responsible for secondary salinity. Increased urbanization and deforestation are two important human derived activities for salinity. A number of reports are on soil salinization and their influences on crop productivity, land degradation and ecologi- cal disturbances are reported worldwide. Excess amount of salts effected physical chemical as well as the biological properties of soils. Plant health in saline soils is considerably decline owing to poor nutrition, osmotic stress and reduced microbial diversity. ${ }^{3}$

Wheat is major cereal crops in India and mainly cultivated in rain-fed areas. Salinity is a major constraint, which hampers wheat production, causing a loss of about $65 \%$ in yield in moderately saline soils. ${ }^{4}$ Salt stress inhibits photosynthesis, protein synthesis, and other metabolic processes in plants. ${ }^{2}$ The development of salt stress tolerant varieties through genetic engineering and plant breeding technology is often innovative technology but a long drawn process taking months to years for successful development. Microbial technology in agriculture is one the needed technology at present and future for sustainable crop productions. 5

Since the elaboration of rhizospheric concept by Hilter in 1904 various rhizospheric microorganisms from different groups have been reported for their plant health promoting activities. The plant growth promoting rhizobacteria not only encourage plant health but emerged as important component of salt stress management. 6,7 The different PGPRs Bacillus, Pseudomonas, Azospirillum, Agrobacterium, Achromobacter, Serratia, have been reported for their PGP activity under different ecological conditions. Among these genus Bacillus the Gram positive and Gram Negative Pseudomonas are most extensively studies rhizobacteria facilitating plant health. B. amyloliquefaciens, B. licheniformis, B. megaterium, B. pumilus, and B. subtilis, are some important member of genus Bacillus and reported for plant growth and stress managements. ${ }^{8,9}$ An increased agricultural production in response to Pseudomaonas inoculation has been reported through different mechanism. ${ }^{10}$ Application of salt tolerant PGPR can be beneficial technology for wheat cultivation in saline areas. PGPR colonise roots and enhances root health through proving nutrient to plants and in return plant provide exudates to PGPR. At present there is dire need of fruitful sustainable agricultural technology in climate change scenarios. The objectives of this study are: i) Isolation and purification of the rhizobacterial strains from saline environment; ii) Efficacy of salt tolerant potential of isolated rhizobacterial strains; iii) Assays biochemical and plant growth promoting traits of salt tolerant strains; iv) In vitro study on potential of selected isolates from Triticum aestivum under soil salinity.
Correspondence: Jay Shankar Singh, Department of Environmental Microbiology, Babasaheb Bhimrao Ambedkar University, Lucknow, Uttar Pradesh 226025, India.

E-mail: jayshankar_1@yahoo.co.in

Key words: Rhizobacteria; Bacillus sp.; Pseudomonas sp.; Soil salinity; Plant growth.

Acknowledgments: the authors thank the Head of the Department of Environmental Microbiology, Babasaheb Bhimrao Ambedkar University for providing all the necessary facilities for this work.

Contributions: SRV designed the experiment and compiled whole manuscript. JG performed experiment. JSS analyzed data, refined scientific languages and guided experiment.

Conflict of interest: the authors declare no potential conflict of interest.

Funding: SRV sincerely thanks University Grants Commission (UGC), Govt. of India, New Delhi, for providing financial support in form of national fellowship (Award No. 39832/17/07/2017).

Received for publication: 23 October 2017. Accepted for publication: 13 April 2018.

This work is licensed under a Creative Commons Attribution NonCommercial 4.0 License (CC BY-NC 4.0).

(C) Copyright S.R. Vimal et al., 2018

Licensee PAGEPress, Italy

Microbiology Research 2018; 9:7462

doi:10.4081/mr.2018.7462

\section{Materials and Methods}

\section{Collection of soil samples}

Soil sample were collected from the rhizosphere of grasses growing on non-fertile saline

soils form the premises of Babasaheb Bhimrao Ambedkar University, Lucknow (Figure 1).

\section{Isolation of rhizobacterial strains}

1 gram of rhizospheric soil was diluted in 9 $\mathrm{mL}$ of MQ water and serially diluted up to 10-6 and spread on nutrient agar media. Plates were incubated for 24 hours at $28 \pm 2{ }^{\circ} \mathrm{C}$ and development of colonies was observed. The colonies were purified and preserved in nutrient agar slants at $4^{\circ} \mathrm{C}$.

\section{Rhizobacterial salt tolerance efficacy}

All the isolates were examined for $\mathrm{NaCl}$ tolerance capacity (up to $1000 \mathrm{mM}$ ) in nutrient broth as well as streaked on NA 
plates. In broth condition growth was monitored with UV-Vis double beam spectrophotometer at $610 \mathrm{~nm}$.

\section{Phenotypic characterization}

Phenotypic characterization of all bacterial isolates was done according to Bergey's Manual of Systematic Bacteriology 2010 (Table 1).

\section{Gram's staining}

Late $\log$ phase culture of isolated strains were smeared on glass slides and fixed under Bunsen burner. The staining of all isolates were done according to Coico $(2005)^{11}$ and observed under phase contrast microscope.

\section{Biochemical tests}

\section{Citrate utilization test}

Citrate utilization test were done according to Koser (1924). ${ }^{12}$ Freshly grown bacterial culture were streaked on Simmon Citrate agar plate and incubated for 24 hours for $28 \pm 2^{\circ} \mathrm{C}$

\section{Amylase production test}

Amylase production test were done according to Palleroni and Holmes (1981). ${ }^{13}$ Spot inoculation was done on starch agar medium and was incubated for 24 hours at $28 \pm 2{ }^{\circ} \mathrm{C}$. After 24 hours the plate was flooded by iodine solution. A transparent zone around colonies appears for positive result.

\section{Catalase test}

The catalase activity was done according to Graham and Parker (1964). ${ }^{14}$ Smear of bacterial culture was made on clean slide with help of inoculating loop. On pouring few drops of $3 \%$ hydrogen peroxide, bubbles of oxygen were observed on the slide.

\section{Casein hydrolysis}

Casein agar hydrolysis was performed with the method of Seeley and Van Demark (1970).15 Skimmed milk agar media were prepared and bacterial strains were spot inoculated on the plates and incubated for 24-48 hour at $28 \pm 2^{\circ} \mathrm{C}$.

\section{Carbohydrate utilization assays}

Twelve carbohydrate utilization tests were examine with carbohydrate utilization kit (Himedia)-Mumbai (KB-009A) India.

\section{Plant growth promoting test of isolated rhizobacterial strains}

\section{Phosphate solubilization}

Phosphate solubilization test were performed according to Pikovaskaya (1948). ${ }^{16}$ Isolated strains were spot inoculated on Pikovaskaya agar medium and incubated for 5-7 days at $28 \pm 2{ }^{\circ} \mathrm{C}$. Phosphate solubilization index (PSI) was calculated by using the formula.

\section{Nitrogen fixation}

N2 fixation ability of isolates were analyse on Jenson $\mathrm{N}$ agar medium according to Jenson (1954). ${ }^{17}$ Appearance of growth on Jenson agar indicates efficiency of $\mathrm{N}$ fixation by isolate.
Siderophore production ability of isolates were determined according to Shwayn and Neilands (1987). ${ }^{18}$ Appearance of orange colour zone on cash dye containing plate shows positive iron chelation.

\section{Hydrogen cyanide production}

The HCN production test was done according to Lorck (1948). ${ }^{19}$ The isolates were subculture on Kings B agar plate supplemented with glycerol $\left(15 \mathrm{~mL} \mathrm{~L}^{-1}\right)$. The filter paper was dip in Picrate $/ \mathrm{Na}_{2} \mathrm{CO}_{3}$ solution and placed on upper lid of Petri plate and incubated at $28 \pm 2^{\circ} \mathrm{C}$ after sealing. Colour changes from yellow to orange, red, brown, or reddish brown was recorded as an indication of weak, moderate, or strongly cyanogenic potential, respectively.

\section{Ammonia production}

The NH3 production of isolated bacterial strains was done according to method of Cappucino and Sherman (1992). ${ }^{20}$ Peptone water broth was prepared in test tubes and was inoculated by bacterial strains and incubated for $48-72$ hours at $28^{\circ} \mathrm{C} .1 \mathrm{~mL}$ of Nesseler's reagent was poured in test tubes. Change in colour from yellow to orange was observed.

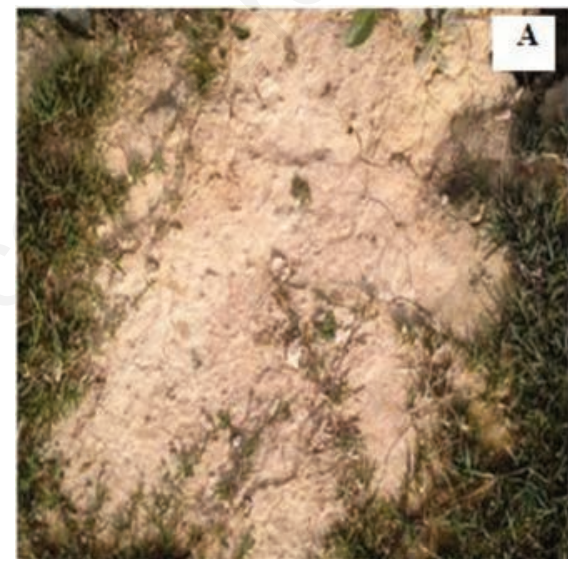

Siderophore production

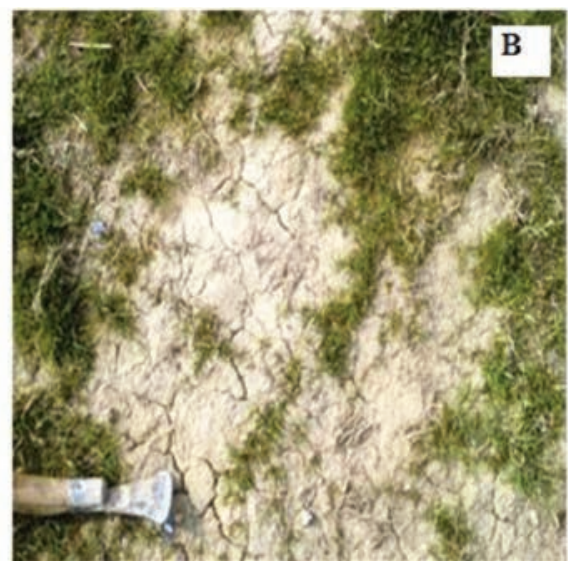

Indole acetic acid production

Figure 1. Photographs of sampling sites of BBAU-Lucknow. (A) Sampling site 1 (B) Sampling site 2 .

Table 1. Phenotypic characterization of selected isolates.

\begin{tabular}{lccccccc} 
Isolates morphology & JG1 & JG2 & JG3 & JG4 & JG5 & JG6 & JG7 \\
Size $(\mathrm{cm})$ & 0.1 & 0.2 & 0.1 & 0.1 & 0.1 & 0.1 & 0.1 \\
Form & Circular & Circular & Circular & Circular & Circular & Circular & Circular \\
\hline Edge & Entire & undulate & Entire & Curled & Entire & Undulate & Entire \\
Elevation & Crateriform & Flat & Flat & Convex & Flat & Convex & Convex \\
\hline Texture & Smooth & Smooth & Smooth & Smooth & Smooth & Smooth & EPS producing \\
Pigment & No & Yes & Yes & No & Yes & Yes & Yes \\
Colour & Off white & White & Off white & Light yellow & Orange & Yellow & Pale yellow \\
\hline
\end{tabular}


The IAA production test was done according to Gorden and Weber (1951). ${ }^{21}$ The strains were inoculated on minimal broth containing different tryptophan concentrations of 50 and $100 \mu \mathrm{g} \mathrm{L}^{-1}$. The test tubes were incubated for $48-72$ hours at $28 \pm 2{ }^{\circ} \mathrm{C}$. The cultures were centrifuged at $6000 \mathrm{rpm}$ for 10 minutes. About $4 \mathrm{~mL}$ freshly prepared Salkowaski reagent is added in $1 \mathrm{~mL}$ of supernatant. Appearance of Cherry Red colour is observed for IAA production. For quantification assay optical density was observed at $530 \mathrm{~nm}$ in double beam UV visible spectrophotometer.

\section{Antibiotic sensitivity test}

The antibiotic sensitivity test was done according to method of Bauer et al. (1996).22,23 This test was performed on Mullar-Hilton agar media plates by placing antibiotic disc of Vancomycin, Kanamycin, Polymyxin-B and Erthromycin. After keeping it for 24-48 hours at $28 \pm 2{ }^{\circ} \mathrm{C}$ zones were formed around the disc were observed.

\section{Experimental design}

In vitro complete randomized design pot experiment was performed to study inoculations effect on wheat plant growth. The plastic pots were filled with sterilized soils introduces with primary salinity according to Bharti et al. (2013). ${ }^{24}$ FYM is used as a carrier in bioformulations yet FYM is also used as organic supplement to soils. The experiment conducted for 4 weeks and irrigation was done with non-saline MQ water. On $29^{\text {th }}$ day the plants were pulled out from pots and analyse for growth parameters.

A. Control (Sterilized soil);

B. Sterilized soil + Farmyard manure;

C. Sterilized soil + Farmyard manure + Strain JG3 (Bacillus sp.);

D. Sterilized soil + Farmyard manure + Strain JG7 (Pseudomonas sp.).

\section{Statistical analysis}

The collected data were subjected to statistical analysis for analysis of variance (ANOVA) performed with IBM SPSS 20.0. All values are in mean of triplicate \pm standard error. The result was considered significant at $p<0.05$

\section{Results}

Rhizobacterial isolates

Total seven salt tolerant rhizobacterial
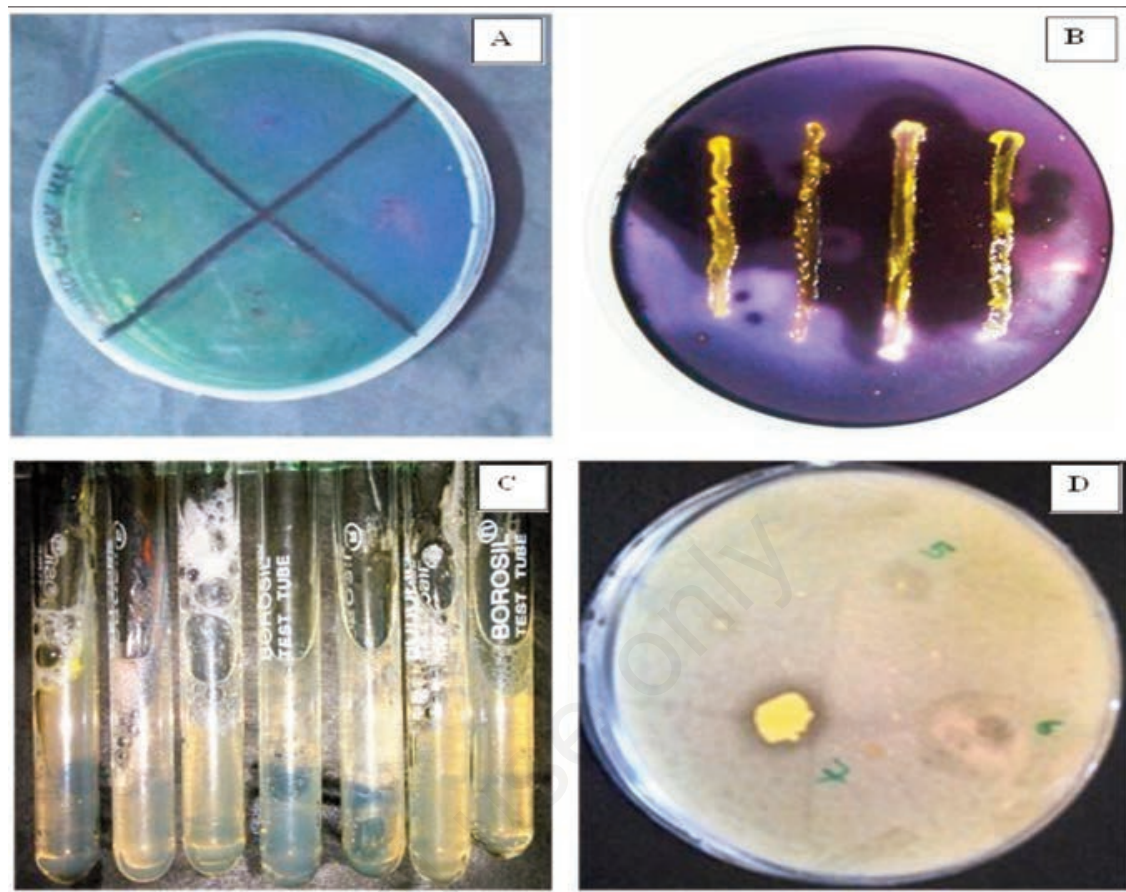

Figure 2. Biochemical activities of isolates. (A) Citrate utilization (B) Amylase production (C) Catalase test (D) Casein hydrolysis.

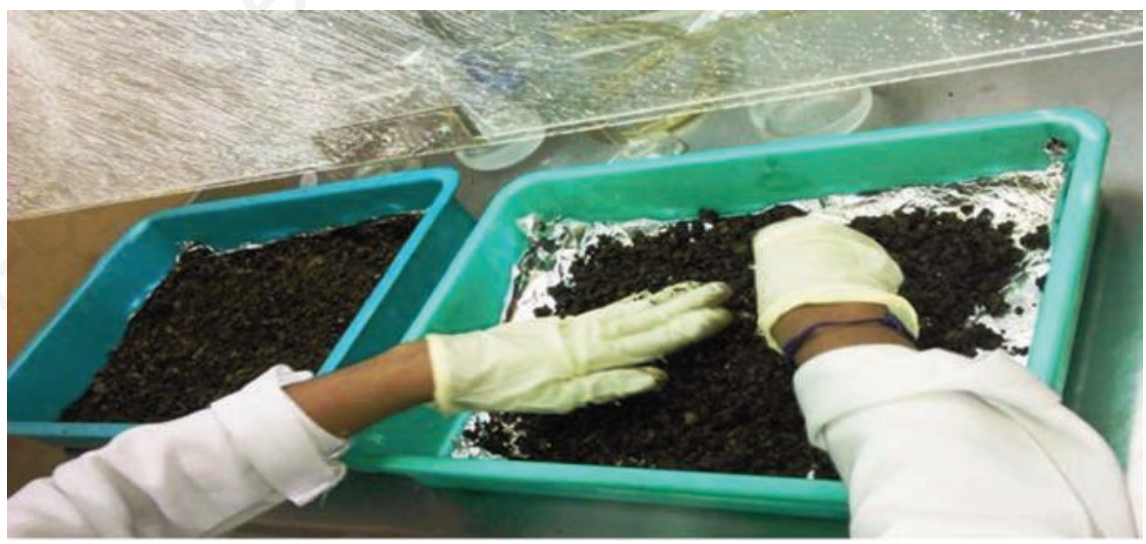

Figure 3. Development of farmyard based formulation with selected isolates in laboratory. Seed bio-priming.

Table 2. Biochemical activities of isolates rhizo-bacterial strains.

\begin{tabular}{|c|c|c|c|c|c|c|c|}
\hline $\begin{array}{l}\text { Biochemical } \\
\text { activities of isolates }\end{array}$ & JG-1 & JG-2 & JG-3 & $J G-4$ & JG-5 & JG-6 & JG-7 \\
\hline Casein hydrolysis & - & - & +++ & + & + & + & ++ \\
\hline Starch hydrolysis & - & - & ++ & - & ++ & + & - \\
\hline Catalase activity & ++ & + & ++ & - & - & ++ & ++ \\
\hline Citrate utilization & - & +++ & - & +++ & - & - & ++ \\
\hline Gram staining & - & + & + & - & - & + & - \\
\hline
\end{tabular}


strains with different morphology on nutrient agar medium were isolated and purified for the study (Table 1).

\section{Biochemical test of rhizobacterial isolates}

Different biochemical test of all seven isolates are described in (Table 2) and shown in (Figure 2). For citrate utilization capacity of isolates only two isolates JG2 and JG4 were found positive and remaining shows negative result for the test. Amylase production efficiency was shown positive by three strains JG3, JG5 and JG6 and other not found positive. For catalase test, out of 7 bacterial isolates, one isolates (JG3) was excellent positive $(+++)$, two (JG1, JG6) were found moderately positive $(++)$ and two strains (JG2, JG7) were slightly positive and two (JG4, JG5) were found negative (-). Strain JG3 was found excellently positive for casein hydrolysis while JG7 moderate positive, JG4 and JG5 slightly positive and JG1 and JG2 are negative for the test.
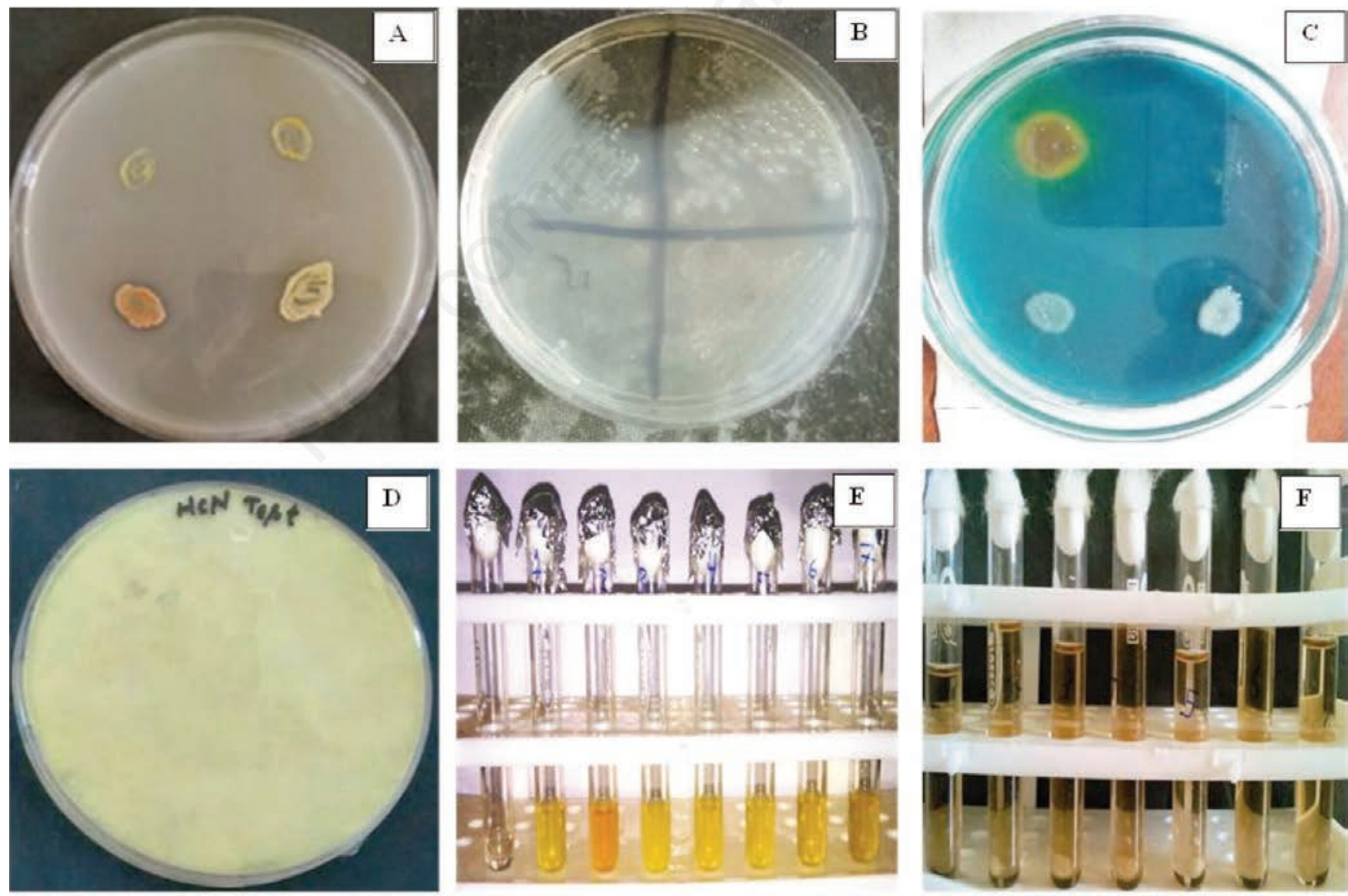

were dipped in sterilized MQ water for control and bacterial suspensions for $10 \mathrm{~min}$ utes and dried overnight in laminar.

\section{Plant growth promoting traits of isolates} were described in (Table 4) and (Figure 4). IAA production was seen highest by strain JG7 $16.3 \mu \mathrm{gml}-1$ followed by strain JG3 $14.8 \mu \mathrm{gml}^{-1}$ with amendment of $100 \mu \mathrm{gL}^{-}$ ${ }^{1} \mathrm{~L}^{-1}$ of tryptophan.

\section{Development of bio-formulation of selected strains}

The bio-formulation of selected best PGPR strains (JG3 and JG7) were done according to procedures of Vidhyasekaran and Muthamilan (1995).23 FYM is used as carrier material for strains (Figure 3).

Wheat cultivars was procured form the local market and were surface sterilized with $70 \%$ ethanol followed by $2 \%$ Sodium hypochlorite solution for $10 \mathrm{~min}$ utes and rinsed in sterile MQ water. Seeds

\section{Comparative study of plant growth parameter}

The comparative experiment was shown in Figure 5. FYM amendment with soil enhances plant height by $10.06 \%$ while inoculation with strain JG3 enhances plant height by $84.56 \%$ and seeds inoculated with JG7 enhance plant height by $48.99 \%$ comparative untreated control (Figure 6A). Root length was increased by $15.62 \%$ in FYM amended soils, $101.56 \%$ in JG3+FYM amended soil, $57.81 \%$ in JG7+FYM amended soil compare to control (Figure 6B). Fresh plant weight was highest in JG3 inoculated plants $83.41 \%$ followed by $51.25 \%$ in JG7 inoculated plants and 14.07\% in FYM amended soils (Figure 6C). While wheat plant dry weight was enhance by $94.04 \%$ in JG3+FYM amended soil $72.61 \%$ in JG7+FYM amended soil and $38.09 \%$ in
Plant growth promoting traits of isolates

Figure 4. Photograph of plant growth promoting traits of salt tolerant isolates. (A) Phosphate solubilization (B) Nitrogen fixation (C) Siderophore production (D) HCN production (E) Ammonia production (F) IAA production. 
FYM treated soil (Figure 6D). Thus in compare to strain JG7 we observe strain JG3 enhances plant height by $32.32 \%$, root length by $37.84 \%$, fresh weight by $28.2 \%$ and dry weight by $15.51 \%$ compared to FYM amended plants.

\section{Discussion and Conclusions}

In the present study seven salt tolerant rhizobacteria were isolated form naturally saline soils and assayed for their plant growth promoting potential and ability to mitigate saline stress of wheat plants. Two best potential isolates on the basis of their morphology and biochemical activities were screened and observed for wheat plant growth promotion under in vitro conditions. These isolates were designated as Bacillus sp. (Strain JG3) and Pseudomonas sp. (Strain JG7). Plant growth promoting rhizobacteria enhance plant health through various known and unknown plant growth promotion mechanisms. ${ }^{24}$ Variety of rhizobacterial strains form both group Bacillus and Pseudomonas are also introduce for plant growth promotion under soil salinity. ${ }^{25}$ In this study, Bacillus sp. (Strain JG3) and Pseudomonas sp. (Strain JG7) were found significant for different PGP traits. Seeds of wheat inoculated with strain JG3 exhibited significant plant growth enhancement than the strain JG7 under primary soil salinity. Wheat plant height, root length, fresh and dry weight was significantly reduced due to salinity stresses. The present study revealed that the variations in

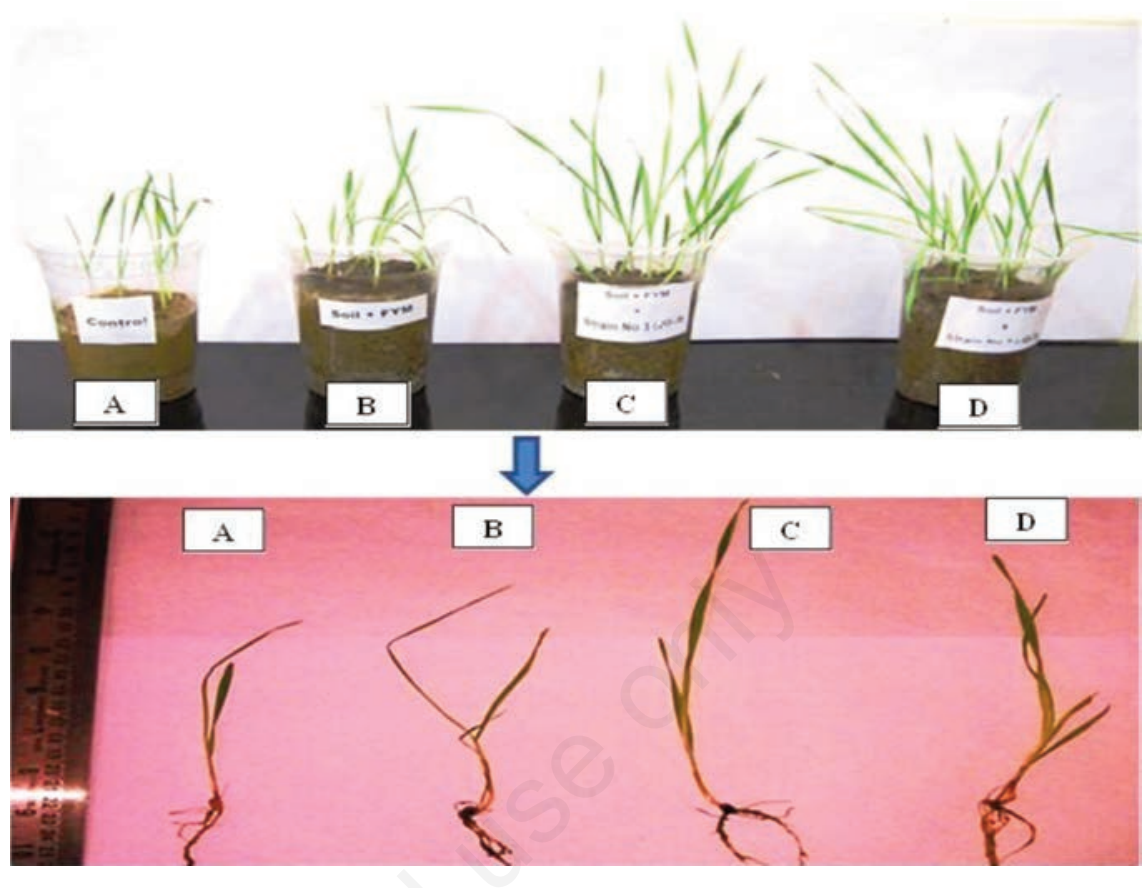

Figure 5. Comparative study of two different isolates on wheat plant growth promotion under secondary soil salinity.

Table 3. Carbohydrate utilization of rhizo-bacterial strains.

\begin{tabular}{|c|c|c|c|c|c|c|c|}
\hline $\begin{array}{l}\text { Carbohydrate } \\
\text { utilization }\end{array}$ & JG-1 & JG-2 & JG-3 & $\mathrm{JG}-4$ & JG-5 & JG-6 & JG-7 \\
\hline Lactose & + & + & + & - & + & - & + \\
\hline Xylose & + & + & - & - & - & - & + \\
\hline Maltose & + & - & - & + & - & + & + \\
\hline Fructose & + & - & + & + & + & + & + \\
\hline Dextrose & + & - & - & + & - & - & - \\
\hline Galactose & - & + & - & - & - & + & - \\
\hline Raffinose & - & - & - & - & - & - & - \\
\hline Trehalose & - & + & + & + & + & - & - \\
\hline Melibiose & - & + & + & - & - & + & - \\
\hline Sucrose & - & - & + & + & + & - & + \\
\hline L-Arabinose & - & - & - & - & - & - & - \\
\hline Mannose & - & + & + & - & + & - & - \\
\hline
\end{tabular}

Table 4. Plant growth promoting activities of isolated rhizo-bacterial strains.

\begin{tabular}{|c|c|c|c|c|c|c|c|}
\hline $\begin{array}{l}\text { PGP traits } \\
\text { of isolated strains }\end{array}$ & JG-1 & JG-2 & JG-3 & $\mathrm{JG}-4$ & $\mathrm{JG}-5$ & $J G-6$ & JG-7 \\
\hline IAA production & + & ++ & ++ & + & + & - & +++ \\
\hline Nitrogen fixation & - & - & +++ & ++ & ++ & - & ++ \\
\hline Siderophore production & - & - & ++ & - & - & - & - \\
\hline Phosphate solubilization & - & + & - & - & - & - & - \\
\hline Ammonia production & + & + & + & + & + & + & ++ \\
\hline HCN production & - & + & + & - & - & - & +++ \\
\hline
\end{tabular}

$(+++=$ excellent positive,$++=$ moderate positive,$+=$ slightly positive, $-=$ negative $)$. 
plant growth parameters between non-inoculated and inoculated plants with JG3 and JG7 were statistically significant (Figure 6). Therefore, it may be concluded the the application of ST-PGPR is innovative and eco-friendly approach for reclamation of degraded agro- ecosystems. Decline demand of agrochemical in crop fields pro- tects soil health and ease detrimental effects on human health. ${ }^{26}$

A

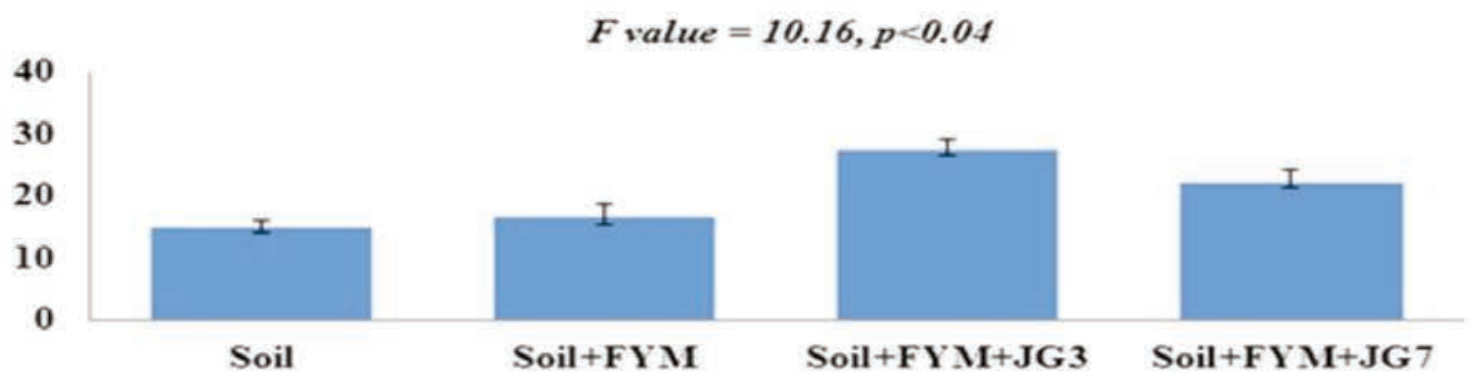

B

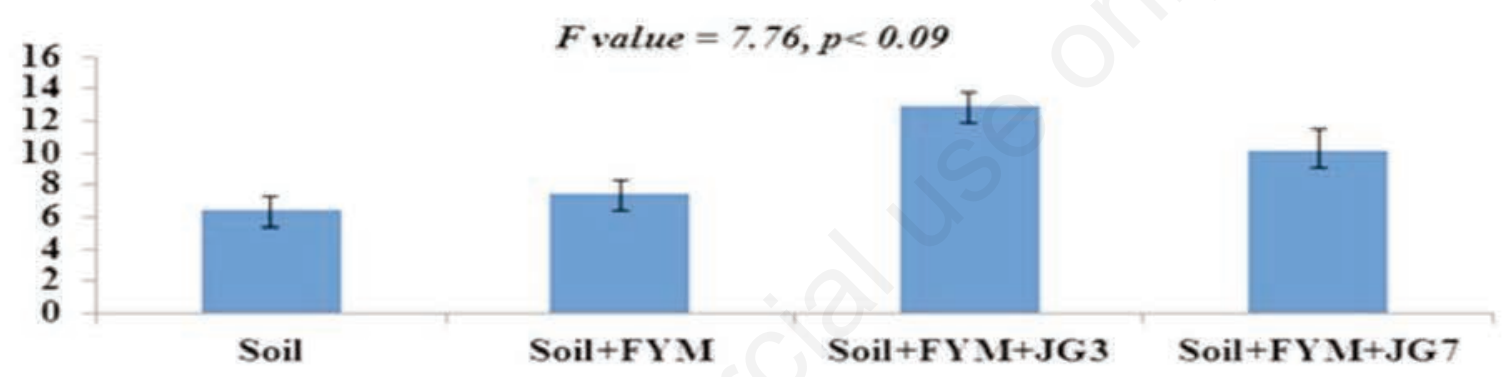

C

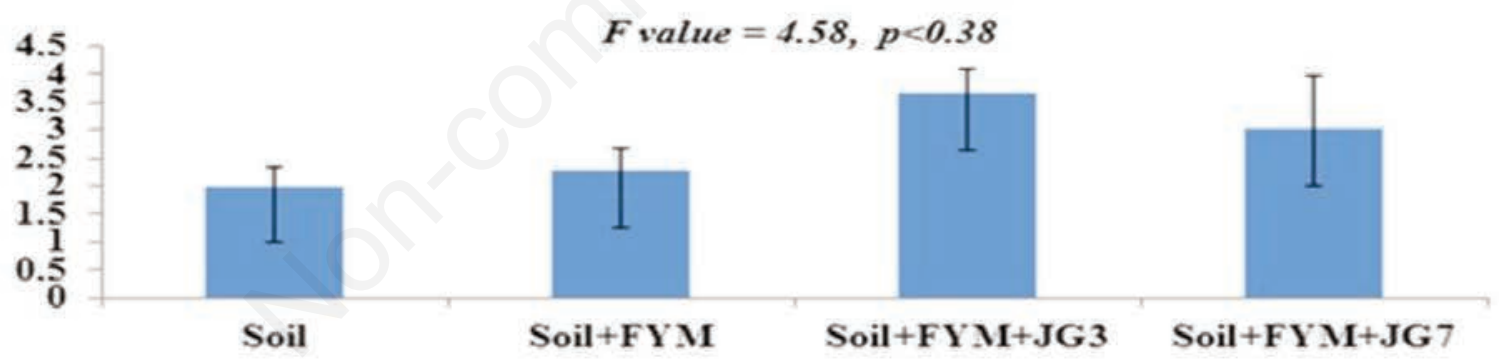

D

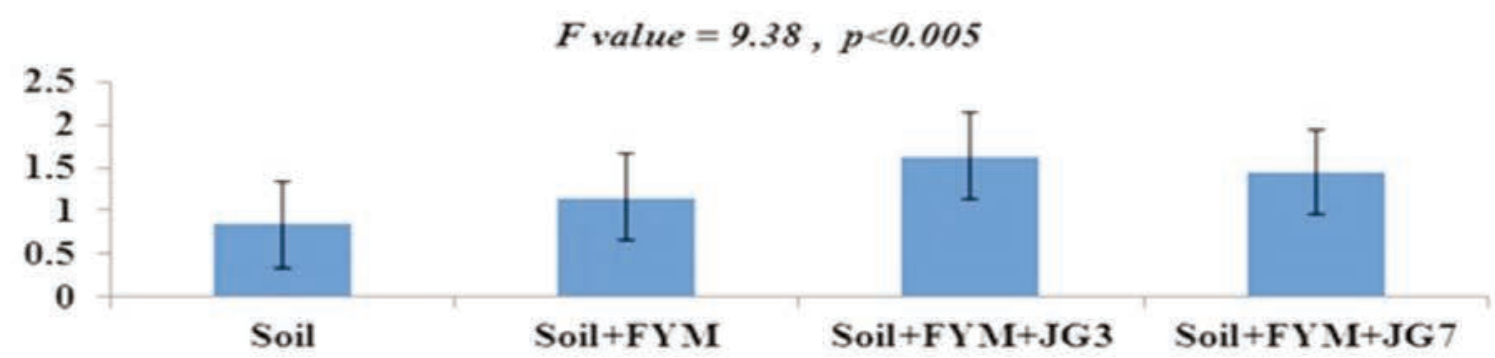

Figure 6. Inoculation effect on plant morphology (A) Plant height (B) Root length (C) Fresh weight (D) Dry weight. 
leaf and rhizosphere community in rice during salt stress. Plant Physiol Biochem 2013;66:1-9.

9. Khan A, Sirajuddin, Zhao XQ et al. Bacillus pumilus enhances tolerance in rice (Oryza sativa L.) to combined stresses of $\mathrm{NaCl}$ and high boron due to limited uptake of $\mathrm{Na}+$. Environ Expt Bot 2016;124:120-129.

10. Egamberdieva D, Davranov K, Wirth S et al. Impact of soil salinity on the plantgrowth- promoting and biological control abilities of root associated bacteria. Saudi J Biol Sci 2017:https://doi.org/ 10.1016/j.sjbs.2017.07.004.

11. Coico R. Gram Staining. Current Protocols in Microbiology. 2005:00:3C:A.3C.1-A.3C.2.

12. Koser SA. Correlation of citrate utilization by members of the colon-aerogenes group with other differential characteristics and with habitat. J. Bacteriol 1924;9:59-77.

13. Palleroni NJ, Holmes B. Pseudomonas cepacia sp. nov., nom. rev. Int J Syst Bacteriol 1981;31: 479-481.

14. Graham PH, Parker CA. Diagnostic features in the characterization of the root nodule bacteria of legumes. Plant soil 1964;20:283-395.

15. Seeley HW, Vandemark PJ. Microbes in action: A laboratory manual of microbiology, D. P. Tarapo Revale Sons and Company Ltd., Bombay. 1970:pp. 8695.

16. Pikovskaya RI. Mobilization of phosphorous in soil in connection with the vital activity of some microbial species. Microbiologia 1948;17:362-370.

17. Jensen HL. The Azotobacteriaceae.
Bacteriol Rev 1954;18:195-214.

18. Schwyn B, Neilands JB. Universal chemical assay for the detection and determination of siderophores. Analytical Biochem. 1987;160:47-56.

19. Lorck H. Production of hydrocyanic acid by bacteria. Physiol. Plant. 1948;1: 142-146.

20. Cappuccino JC, Sherman N. In: Microbiology: A Laboratory Manual, third ed. Benjamin/cummings Pub. Co., New York, 1992:pp. 125-179.

21. Gordon SA, Weber RP. Colorimetric estimation of indole acetic acid. Plant Physiol 1951;26:192-195.

22. Bauer AW, Kirby WM, Sherris JC et al. Antibiotic susceptibility testing by standardized single disc method. Am J Clin Pathol. 1996;44:493-496.

23. Vidhyasekaran P, Muthamilan M. Development of formulations of Pseudomonas fluorescens for control of chickpea wilt. Plant Disease 1995;79:782-786.

24. Cardinale M, Ratering S, Suarez C et al. Paradox of plant growth promotion potential of rhizobacteria and their actual promotion effect on growth of barley (Hordeum vulgare L.) under salt stress. Microbiol Res 2015;181: 22-32.

25. Upadhyay SK, Singh DP. Effect of salttolerant plant growth-promoting rhizobacteria on wheat plants and soil health in a saline environment. Plant Biol 2015;17:288-293.

26. Singh JS, Abhilash PC, Gupta VK. Agriculturally important microbes in sustainable food production. Trend Biotechnol 2016; 34:773-775. 